\title{
Exploring SoTL through International Collaborative Writing Groups
}

\begin{abstract}
This article outlines an initiative to explore aspects of the Scholarship of Teaching and Learning (SoTL) through facilitating international collaborative writing groups (ICWGs) in a year-long process. The principles and methods by which the topics and groups were selected and how the writing process was supported are described, and an initial discussion of the initiative's outcomes and the participants' experience is provided. The article concludes with a brief introduction to the set of papers produced by the groups included in this special issue.
\end{abstract}

\section{KEY WORDS}

collaborative writing, international co-authoring, scholarship of teaching and learning, writer's experience

\section{ORIGINS}

The idea for this collection of papers and, just as importantly, the process by which they would be developed, arose in a conversation the three authors had at ISSOTL11 in Milwaukee. Before the end of the conference, we had the structure in place and the wholehearted support of the ISSOTL Board. Moreover, the editors of the new ISSOTL Journal Teaching \& Learning Inquiry were keen in principle to devote an issue of the journal to the resulting papers. The main aims of the initiative were twofold: a) to build the capacity of participants to work and write in international collaborative groups, and b) to contribute to the literature on aspects of a range of SoTL topics from an international perspective. Most of the writing was done at a distance, but the key part of the process was a 48-hour residential event prior to the commencement of the ISSOTL12 conference in Hamilton, Canada, in October 2012.

The process was based on one developed by the International Network for Learning and Teaching Geography in Higher Education (INLT) and applied successfully on four previous occasions, each of which led to sets of articles being published in the Journal of Geography in Higher Education (Healey, Foote and Hay, 2000; Healey, 2006; Pawson, 2008; Solem, 2010). Two of us had experienced this process through INLT (Mick and Susan). We wished to give as many people as possible the opportunity to participate in the initiative, and we felt that we could build on our previous experience and facilitate up to nine groups, each with six or seven members and a chair. 


\section{PRINCIPLES AND METHODS}

The broad topic areas were chosen in consultation with colleagues invited to lead each of the nine groups. They fell into two groups: a) the practice of SoTL and b) the scholarship of academic practice. The topics chosen were deliberately broad so that the individual groups could decide on their own focus and contribution. In choosing the people to invite to chair the groups, we invited colleagues who we believed had the ability to lead and encourage participants to write collaboratively and complete the articles on time. That said, we wanted an international group of chairs at a range of levels of seniority and who were interested in a range of topics around the practice of SoTL and the scholarship of academic practice. All but one of the people we initially approached was able and enthusiastic to participate; one other later had to withdraw part way through the process in the transition to a new job, and we asked a member of their group to takeover the leadership.

The call for people to participate in the initiative went out early in 2012 on a variety of listserves. We had over twice as many applicants as there were places, and the final groups were chosen so that as far as possible each contained the following:

a) a wide international coverage,

b) a mixture of junior and senior faculty and at least one student, and

c) participants from a range of disciplines.

The insistence on inclusion of student members was an innovation not undertaken by the INLT. A few people dropped out near the beginning of the process, sometimes because they were unable to obtain the funding to participate at the residential event; where possible, substitutes were found from a reserve list. Nine scholarships were provided to subsidize the costs of student members.

The groups were formed in April 2012, and 69 people met in Hamilton in October. Thirteen different countries were represented, although three-quarters of the participants were from Canada, the United States, or the United Kingdom. The final papers were due in January 2013. In total, eight papers were submitted on time and sent on to Teaching \& Learning Inquiry for review. To avoid delays, we waited to include our comments with those of the reviewers.

\section{SUPPORTING THE WRITING PROCESS}

It was left to the individual chairs how they wished to run their groups. However, a web conference meeting of chairs was held six weeks into the process to exchange ideas. We also had individual conversations with most of the chairs. It helped that three of the chairs, as well as two of the facilitators, had previous experience of the INLT process and could identify issues which were likely, or just as importantly unlikely, to arise and how these had been tackled previously. Most of the pre-conference period was spent by groups discussing the possible focus of their papers, defining terms, and drafting 2000word synopses of their proposed papers. Although it was emphasised that the papers should largely be conceptualisations based on a review of the relevant literature, a few groups decided to collect some primary data on their agreed topic. The paper proposals were posted on a dedicated section of McMaster's virtual learning environment in September. Each participant was then asked to comment on at least two of the papers, one pre-allocated and another of their choice. 
The participants met face-to-face, many for the first time, at a dinner on the evening prior to the two-day meeting in Hamilton, just before the 2012 ISSOTL conference. The program for the workshop itself was designed to give a mixture of individual and whole group meetings. The latter included a brainstorming session on clarifying the focus and contribution of their papers, a short presentation and discussion of each group's proposed paper (in two parallel groups), and a liquid café session (Seel, 2006) in which each group posed a question with which they wanted help. By the end of the two days, each group had refined their papers, sometimes quite radically, and had agreed on a plan to complete their articles by the submission deadline of mid-January 2013. A further web conference with the chairs was held six weeks after the residential to review progress.

\section{INITIAL FINDINGS ON PARTICIPANTS' EXPERIENCES}

In parallel with the process of supporting the ICWGs prepare their papers, we conducted an action research project designed to explore individuals' experiences of participating in this initiative and their perceptions of its impact. In September 2012, following obtaining ethical approval, various stakeholders (ICWG participants and group chairs, ICWG facilitators, ISSOTL Board members, and the editors of Teaching \& Learning Inquiry) were invited to participate in a brief online survey, which asked for their perceptions of the initiative to date. The survey also invited interested participants to take part in a focus group or an interview relating to the ICWG immediately following the two-day workshop in Hamilton. Finally, a follow-up survey conducted in March 2013 invited the same groups of stakeholders that completed the first survey to offer their reflections on the initiative as a whole.

A thorough discussion of the results of this research is beyond the scope of this article and will be provided elsewhere presently. In order to offer some sense of the initiative's impact beyond the articles included in this issue, we report briefly here on the results of a short feedback exercise that was conducted at the end of the residential workshop in Hamilton in October 2012. This exercise asked participants to reflect on the ICWG process to date, and particularly on the residential workshop they had just experienced, and to offer some feedback about the extent to which it had met four goals related to our central ICWG objectives. These were a) building the capacity of participants to write about SoTL in teams, b) promoting effective international connections and collaborations, c) making meaningful contributions to the SoTL literature, and d) facilitating the development of friendships and having fun (goals which we saw as underpinning each of the previous three, as well as fundamental in their own right).

In terms of capacity building, several participants highlighted the way in which the mixture of people in each group (including senior and junior scholars and students) from a range of different countries provided a valuable opportunity for development by encouraging meaningful partnering and mentorship. They felt that the initiative helped them to learn to write collaboratively by establishing a structured opportunity to exchange ideas and learn from others. Some suggested that the ICWG's capacity-building potential could be enhanced by extending the time involved, and thus allowing further group development, and by providing additional opportunities for students to become involved and to connect with one another.

Feedback about the initiative's capacity to foster international collaborations suggested that the wide international participation worked to expose differences in termi- 
nologies and frameworks, enhancing the potential for collaborative work as a result. Several participants also believed the process could lead to future collaborations with other ICWG participants. Suggestions for augmenting the initiative's success in this area included recruiting participants from more diverse locations and offering some type of follow up reunion to encourage ongoing conversation and maintain the connections formed.

Several participants noted that the ICWG experience contributed to the development of SoTL by presenting a novel way of thinking about and cultivating literature in the field. Many also emphasized the value of an approach that brings together multiple perspectives around a key theme in a single article. Ideas for increasing the initiative's contributions to the SoTL literature included tinkering with the program for the residential workshop in ways that participants believed would allow for greater development of the articles being written, including allowing more time for working in their groups, and soliciting suggestions for topics from the full set of potential participants, rather than inviting people to write on pre-selected themes decided in collaboration with the group leaders.

Feedback surrounding the final goal, relationship building, suggested that the inclusion of social times and meals (such as the initial dinner) successfully facilitated connections and informal discussions and provided an opportunity to reconnect with old friends or to make new ones. The positive and open-minded attitudes of participants were also noted frequently. Additional team-building activities and ice-breakers, as well as more opportunities to connect with people outside of one's individual group, were proposed as means to enhance the initiative's capacity for relationship building still further.

In many respects, this feedback dovetails with our own experiences of the initiative, echoing our sense of some of its major challenges and successes. In particular, we too felt the desire for more time during the residential workshop and struggled with the tension between providing opportunities for full group networking and maximising the chances for the groups to work on their specific papers. A further four to six hours on a third day might be a useful addition to the process, though this would result in an increase in cost and a potential decrease in the number of participants able to commit to taking part. Overall, however, we are extremely pleased with the generous and generative international collaborations we have witnessed taking place over the course of this year-long project, and with the contributions to the SoTL literature it has produced.

\section{THE PAPERS}

In this special issue, we have structured the papers in the same two groups identified in the ICWG initiative. There are five papers concerned with international perspectives on an aspect of the practice of SoTL:

- Conflicts and configurations in a liminal space: SoTL scholars' identity development (Simmons, Abrahamson, Deshler, Kensington-Miller, Manarin, Morón-García, Oliver, and Renc-Roe)

- Being ethically minded: Practising the scholarship of teaching and learning in an ethical manner (Healey, Bass, Caulfield, Hoffman, McGinn, Miller-Young, and Haigh)

- The scholarship of teaching and learning in an age of accountability: Building 
bridges (Hutchings, Borin, Keesing-Styles, Martin, Michael, Scharff, Simkins, and Ismail)

- The power of social networks: A model for weaving the scholarship of teaching and learning into institutional culture (Williams, Verwoord, Beery, Dalton, McKinnon, Strickland, Pace, and Poole)

- A call for expanding inclusive student engagement in SoTL (Felten, Bagg, Bumbry, Hill, Hornsby, Pratt, and Weller)

and a further three explore international perspectives on an aspect of the scholarship of academic practice:

- SoTL and student experiences of their degree-level programs: An empirical investigation (Matthews, Divan, John-Thomas, Lopes, Ludwig, Martini, Motley, and Tomljenovic-Berube)

- Followership in higher education: Academic teachers and their formal leaders (Billot, West, Khong, Skorobohacz, Roxå, Murray, and Gayle)

- Completing the research cycle: A framework for promoting dissemination of undergraduate research and inquiry (Spronken-Smith, Brodeur, Kajaks, Luck, Myatt, Verburgh, Walkington, and Wuetherick)

The first paper in the collection explores some of the identity changes experienced with becoming a SoTL practitioner and the associated tensions and configurations. Simmons et al. suggest that these experiences may be interpreted using the idea of liminal spaces. An important aspect of becoming a SoTL practitioner is also to become ethically minded. In the second paper, Healey et al. explore the idea of "ethical SoTL" and develop an "ethical SoTL matrix" to support practitioners designing their inquiries. Their argument is that "SoTL practitioners should reflect on different [ethical] perspectives as they consider possible actions in their efforts to do what is right in any given situation." The focus of the next two papers switches more to the institutional level. Hutchings et al. explore how the international move to increased accountability can cause not only tensions for institutions developing SoTL programs but also opportunities, while Williams et al. propose a model for embedding SoTL within institutions based on social network theory. Both papers suggest that students should be part of the SoTL discourse. This theme is taken up explicitly in the last paper in this group. Felten et al. argue cogently for expanding student participation in SoTL, noting that "inclusive engagement has tremendous potential to enhance student and faculty learning, to deepen SoTL initiatives, and to help redress the exclusionary practices that too often occur in higher education."

The remaining three papers in the collection explore a variety of aspects of the scholarship of academic practice. In the first paper, Matthews et al. analyse 136 articles published recently in international SoTL journals and argue that greater attention should be paid to the learning part of SoTL by focusing on the student experience of their whole degree program. They suggest that such a shift "would provide much-needed evidence to inform curricular review processes, as well as make an important contribution to broader social and political discussions about the value of university degree programs." Billot et al. also undertake an empirical investigation in their examination of the under-researched area of followership in higher education. They analyse 38 narratives from academic teachers 
in seven institutions worldwide describing the experience of being a follower interacting with a formal leader. They conclude that "in challenging times, academic leaders must attend to the characteristics and needs of their followerships." The final paper also investigates an area that has been given limited attention in the literature. Spronken-Smith et al. argue that, with the expansion of undergraduate research and inquiry, it is important to give students the opportunity to disseminate their findings. They develop a "research dissemination framework," which links the level of exposure involved in dissemination with the extent of student autonomy, and illustrate it with a set of case studies from different countries.

We hope that the readers of Teaching \& Learning Inquiry will enjoy this collection of papers from the first ISSOTL International Collaborative Writing Groups' Initiative and will find both the product and the process of the initiative as stimulating as we have. Our sincere thanks are due to all of the writing group members and leaders for their active and energetic engagement throughout the process, and to the editors and reviewers of Teaching \& Learning Inquiry for their insightful commentary and unflagging support.

Mick Healey is an HE Consultant and Researcher and Emeritus Professor at the University of Gloucestershire, UK.

Beth Marquis is an Assistant Professor in the Arts \& Science Program at McMaster University, Hamilton, Canada.

The late Sue Vajoczki was Director of the Centre for Leadership in Learning and an Associate Professor in the School of Geography and Earth Sciences at McMaster University.

\section{REFERENCES}

Healey, M. (ed.). (2006). International perspectives on selected issues in the learning and teaching of geography in higher education, Journal of Geography in Higher Education, 30(1), 63-160.

Healey, M., Foote, K., \& Hay, I. (eds.). (2000). International perspectives on learning and teaching geography in higher education, set of nine papers, Journal of Geography in Higher Education, 24(2), 217-298.

Pawson, E. (ed.). (2008). The INLT symposium: Brisbane 2006, Journal of Geography in Higher Education, 32(1), 33-149.

Seel, R. (2006). Liquid café. Retrieved from http://www.new-paradigm.co.uk/liquid_cafe.htm

Solem, M. (ed.) (2011). Changing geography in higher education: Towards a scholarship of academic practice: Papers from the 2010 INLT workshop, Journal of Geography in Higher Education, 35(3), 311-455. 